OAI-PMH: http://www.indteca.com/ojs/index.php/Revista Scientific/oai

Artículo Original / Original Article

\title{
El Proyecto Pedagógico de Simón Rodríguez para la Educación en Ecuador
}

Autor: Silverio Jesús González Téllez Universidad Nacional de Educación, UNAE silverio.gonzalez@unae.edu.ec

Azogues, Ecuador https://orcid.org/0000-0002-2004-4372

\section{Resumen}

El presente trabajo analiza los aportes de Simón Rodríguez (1771-1854) al proyecto pedagógico de la educación en Ecuador. Para ello, se empleó el análisis y revisión bibliográfica de su obra titulada Consejos de amigo dados al Colegio de Latacunga del año 1851, para comprender sus propuestas para la educación en Ecuador. Se identificó que su proyecto concibe a la escuela y a la educación social como espacio de creación de una nueva autoridad para una nueva sociedad.

Palabras clave: proyecto de educación; sociedad; educación; historia.

Cómo citar este artículo:

González, S. (2019). El Proyecto Pedagógico de Simón Rodríguez para la Educación en Ecuador. Revista Scientific, 4(14), 308-327, e-ISSN: 2542-2987. Recuperado de: https://doi.org/10.29394/Scientific.issn.2542-2987.2019.4.14.15.308-327

Fecha de Recepción: 06-07-2019
Fecha de Aceptación:

18-09-2019
Fecha de Publicación:

05-11-2019 


\title{
The Simón Rodríguez Pedagogical Project for Education in Ecuador
}

\begin{abstract}
This paper analyzes the contributions of Simón Rodríguez (1771-1854) to the educational project of education in Ecuador. For this, the analysis and bibliographic review of his work entitled Friend's advice given to the College of Latacunga in 1851 was used to understand his proposals for education in Ecuador. It was identified that his project conceives school and social education as a space for creating a new authority for a new society.
\end{abstract}

Keywords: educational project; society; education; history.

Date Received:

06-07-2019
Date Acceptance:

18-09-2019
Date Publication:

05-11-2019 


\section{Introducción}

Simón Rodríguez (1771-1854), salió de Caracas, su ciudad natal, a los 28 años, para no regresar nunca más. Como lo expone su biógrafo ecuatoriano Rumazo (2006a), Rodríguez lo hizo por consecuencias de su participación en la revuelta independentista fracasada de Gual y España en el año 1797 (págs. 28-29). Su regreso a Sudamérica sólo ocurre después de 26 años, luego de un amplio periplo internacional, cuando desembarcó en el puerto de Cartagena en el año 1823. Su motivo de regreso fue participar de la fundación de la nueva República de Colombia. De Cartagena remontó a Bogotá en búsqueda del otro Simón (Bolívar). Pero éste se había ido a la campaña del sur por la independencia de Perú.

Poco tiempo demoró en Santa Fe de Bogotá. A los meses embarcó hacia Guayaquil, desde Panamá, en respuesta al llamado de Bolívar, quien ya lo sabía en tierra colombiana. Al entrar al océano Pacífico navegó por el mar que nunca más dejaría, según Uslar-Pietri (1981a): su "mar final" (pág. 185). $Y$ Guayaquil, fue su centro, puerto y escala de tantas idas y venidas a la sierra andina y a otras ciudades de la costa americana, desde su arribo a esa ciudad, en el año 1824. Eran las vísperas de la batalla de Ayacucho. Le tocó saborear desde allí el triunfo republicano sobre las tropas del Virrey La Serna. Ese tiempo de gloria fue la oportunidad de Rodríguez para encontrarse con El Libertador. De acuerdo con Uslar-Pietri (1981b): ocurrió en Lima. Allí Rodríguez, ratificó a Bolívar una de sus máximas sentencias: en nuestra América, las repúblicas están establecidas, pero no fundadas, hay que formar republicanos sobre una herencia de despotismo y monarquía (págs. 197-198). Plantea Grases (1981): que Rodríguez propone una emancipación ya no militar y política, sino social y económica (pág. 57); donde, según Paladines (2008a): la escuela primaria sería el centro de esa formación (pág.163).

Rodríguez fue nombrado por orden de Bolívar, Director General de Educación en Chuquisaca, en el Alto Perú, Bolivia, el año 1826. Pero los 
desencuentros con el Mariscal Sucre culminan con su salida del cargo en el año 1827.

Se marcha a vivir y trabajar por años en Arequipa, Concepción y Valparaíso, hasta que remonta a Quito en el año 1842. De acuerdo con UslarPietri (1981c): fue cuando le ofrecieron una cátedra de agricultura y botánica en el Colegio de San Vicente de Latacunga, al sur de Quito. Pero de nuevo, los revuelos de las guerras internas y los cambios de gobierno terminaron su primera experiencia en ese colegio (pág. 319). Los últimos diez años de su vida los pasó de una ciudad a otra en Ecuador y cercanías. En realidad, señala Uslar-Pietri (1981d): "nada había conocido tanto como Ecuador" (pág. 34). Llegó hasta la frontera norte con Colombia y finalmente murió en Amotape, en Perú, cerca de la frontera sur del Ecuador con Perú. Su última década de vida está marcada por ese ir y venir en la geografía andina, en torno a su obra, y en su visión ya madurada sobre la educación social. Para Rumazo (2006b): "los Consejos de amigo dados al Rector del Colegio de Latacunga" (pág. 127); fue su última obra orgánica escrita en su segunda estadía en esa ciudad.

El texto, con el mismo nombre, fue escrito entre los años 1850 y 1851 , cuando ya el autor tenía 80 años, y, según Cúneo (1981a): fue descubierto un siglo después por Aureliano Espinosa en la Biblioteca de la Universidad Católica del Ecuador de Cotocollao, y del cual una selección fue publicada en el libro "Inventamos o Erramos" (pág. 199). Es ese texto el que se propone analizar aquí.

De la dilatada actividad de Rodríguez se puede rescatar la influencia educativa que tuvo en el niño y en el joven Bolívar, siendo su momento culminante el acompañamiento a Bolívar en su juramento en el Monte Sacro de Roma. Allí Rodríguez fue inspirador del viaje a Italia, y único testigo de la expresión de la voluntad y el compromiso del joven Simón Bolívar por la libertad de América del imperio español. Para Bolívar (1824a), Rodríguez es: "Sócrates de Caracas... mí Sócrates" (pág. 172); y le da la bienvenida a la 
Gran Colombia, diciéndole "no he podido borrar siquiera una coma de las grandes sentencias que Ud. me ha regalado" (pág. 172).

Otro gran aporte de Rodríguez, fue su obra escrita, que la maduró y atesoró a lo largo de tantas reflexiones, encuentros, viajes, penurias y experiencias difíciles. Lamentablemente sólo conocemos una parte de ella, por cuanto, tal y como manifiestan Calderón y Fierro (2013a): el incendio de Guayaquil en el año 1896, acabó con manuscritos y textos del autor (pág. 23). En síntesis, la obra de Rodríguez ha sido valorada por García-Bacca (1990a), en los siguientes términos:

El Sócrates de Caracas fue realmente filósofo cosmopolita. Cosmopolita geográficamente, por de pronto: Jamaica, Estados Unidos, Francia, Suiza, Austria, Polonia, Rusia, Italia, Prusia, Inglaterra; y en América, Venezuela, Colombia, Ecuador, Perú, Chile, Bolivia. Y no de espectador curioso, sino de conviviente en vida, lengua, magisterio, penurias, goces, acontecimientos históricos en muchas de tales Naciones; más de ciudadano en otras, sobre todo y ante todo en la Gran Colombia (págs. XVI-XVII).

Sus experiencias prácticas y políticas en la creación de un nuevo sistema educativo fueron puntuales y difíciles, desde Caracas hasta Latacunga. Sin embargo, a pesar de ser un hombre de reflexión y acción, con propuestas muy concretas, no pudo superar los inmensos obstáculos políticos, culturales y económicos que enfrentó su visión de la educación como fundadora de otra sociedad. El presente trabajo propone rescatar el valor y significado de la visión social y educativa de Rodríguez en Consejos de Amigo..., conceptualizada por Paladines (2008b): en términos de "proyecto pedagógico específico" (pág. 167).

\section{Metodología}

Para Prieto (1987): concuerda que la obra de Rodríguez es un esfuerzo comunicativo pedagógico particular que denuncia tempranamente el 
neocolonialismo (págs. 27-28). Para Rodríguez la forma es muy importante en la pedagogía y por tanto también en su comunicación. Señala Alfaro (1999): señala que en esto se adelantó a propuestas innovadoras de "hablar con imágenes" (pág. 17); que relaciona la educación y la comunicación para la creación de "sujetos de aprendizaje" (pág. 18). La escritura de Rodríguez es logo-gráfica, con expresión de sensibilidad y emoción, en el sentido mencionado por Rotker (1995): en el cual se trata de "pintar las ideas", a manera de resaltarlas, o de "resucitar ideas sepultadas en el papel" (pág. 162). En tanto que para Urosa (2015): concuerda en que se trata de revivir los significados muertos de las palabras a través de una escritura de intensidades (pág. 219). Y al mismo tiempo, afirma Gutiérrez (2011): Rodríguez parte siempre de la razón, para "la aplicación de esquemas de razonamiento lógicomatemáticos... acudiendo a procedimientos tales como: paralelismos, analogías, series, progresiones, operaciones aritméticas, inversiones, condicionales, equivalencias, asociaciones transitivas, etc." (pág. 31). Para lo cual las reglas ortográficas, los espacios y los tamaños de las letras son alterados. Por ello Paladines (2008c), afirma que: "la semiótica adquirió en Rodríguez un determinado estatuto epistemológico, que permite hablar de él como un precursor de dicha ciencia" (pág. 162).

\section{Análisis e Interpretación de resultados}

El presente trabajo mantiene, en lo posible, parte del formato original a través de una citación gráfica de su obra, así como con la misma ortografía utilizada. Se escogen varios segmentos textuales, los cuales se consideran claves en la obra final de Rodríguez que se propone analizar aquí, a fin de identificar las principales categorías de análisis de su propuesta educativa (resaltadas en mayúsculas, itálicas y negritas), las cuales se discuten y analizan a través de una triangulación de sus significados con otros importantes análisis de su obra escrita y existencial. A manera de ejemplo, la 
figura 1, muestra una página de Rodríguez seleccionada por García-Bacca, para sustentar este punto tan relevante de la obra a analizar.

Figura 1. Ejemplo de escritura logo-gráfica de Simón Rodríguez titulada: La fuerza de la autoridad.

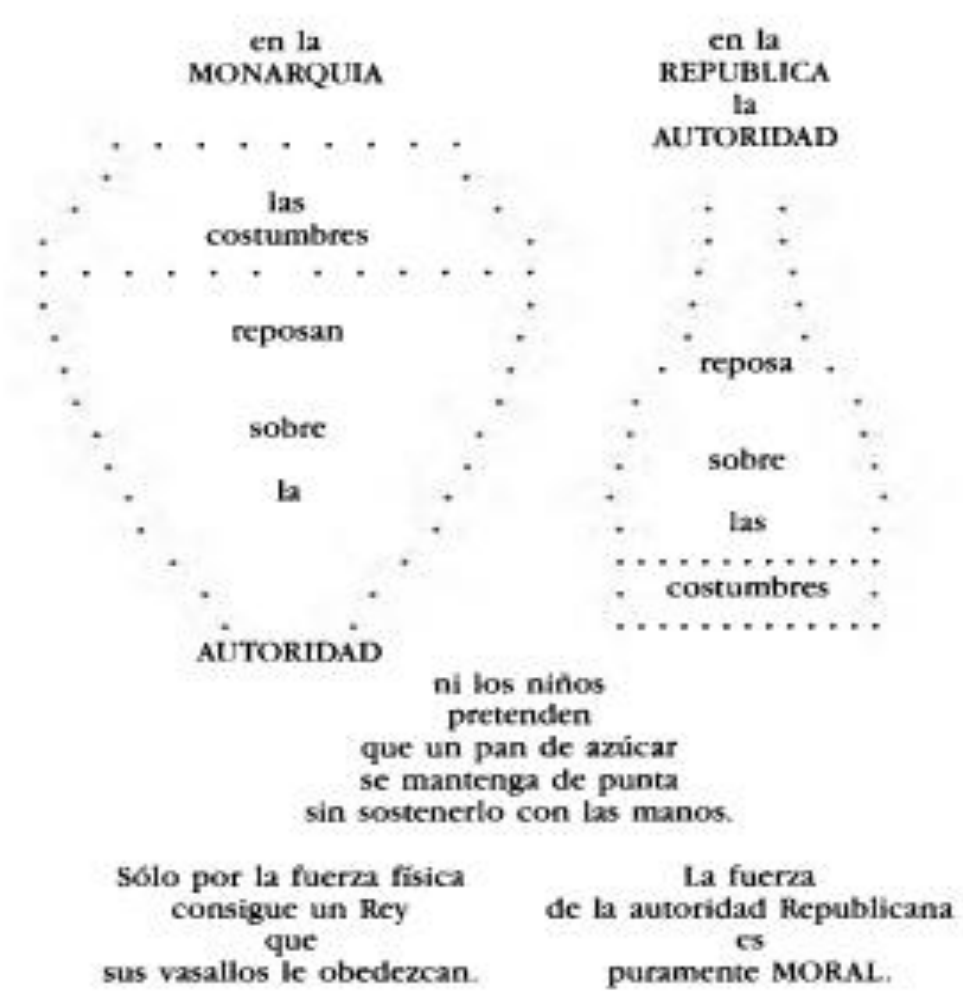

Pregunten los Soberanos Congresos a su Poder Ejecutivo, si con ta Boca sola da sus 6rdenes, y si sus Agentes, para hacerlas cumplir, van con las manos vactas.

Fuente: García-Bacca (1990).

El texto que aquí se analiza (Consejos de Amigo...) comienza con una ponderación del valor de la escuela para la sociedad. En un estilo directo hacia el Rector Quevedo, del Colegio de San Vicente en Latacunga, le recomienda que si no quiere perder su esfuerzo se concentre en una premisa clave de la realidad contextual de la sociedad andina: su población indígena. Para esto, Rodríguez (1982a), exterioriza LOS DUEÑOS DEL PAÍS: 
Emprenda su Escuela con... INDIOS!!! Bien merecen los DUEÑOS DEL PAÍS - los que mantienen el Gobierno i la Iglesia con su DINERO, i a los Particulares con su Trabajo, que enseñen a sus hijos a Hablar, a Escribir, a llevar Cuentas, i a tratar con DECENCIA... (pág. 203).

Él funda la base del contrato social republicano, asociativo e incluyente, en la primera escuela (o escuela básica), y en la sociabilidad que ella debe practicar. Los hijos de quienes sostienen el país merecen recibir de la escuela su incorporación a la sociedad. Y esos que sostienen el país son los ciudadanos de la república, mayormente indígenas, en el Ecuador del año 1850. De allí que Rodríguez (1982b): propone no cualquier escuela a la europea, sino una escuela reformada, una "ESCUELA SOCIAL", que sea suplente de "la potestad paterna en la labor de enseñar" (pág. 205); por lo cual, la enseñanza es primero que nada de "lo que es derecho y deber, en Sociedad" (pág. 206). Punto fundamental en la complementación de la familia en la fundación republicana y asunto muy delicado en la sociedad de la época. En esa misma línea de reflexión propone formar maestros antes de abrir escuelas. Para Rodríguez (1982c), PRIMERO SON LOS MAESTROS: "formar maestros, ántes de abrir Escuelas... así serán las Escuelas, i así saldrán los Niños de ellas" (pág. 208).

A partir de esas premisas lanza varias sentencias teóricas y dos consejos, para enmarcar y fundamentar una propuesta de escuela con aspectos curriculares, fondo productivo en tierras cultivables, maestranza, contratación de maestros y principios de rectoría del colegio. Comenzaremos por las sentencias. La primera tiene que ver con la formación de la vida social. A este argumento, Rodríguez (1982d), presenta LA RESISTENCIA INSTINTIVA A LA VIDA SOCIAL:

La Vida no es más que hábitos i costumbres... todos los movimientos, todos los actos, vienen a ser...con el tiempo.... INSTINTIVOS... no obstante como NADA es CONSTANTE, en 
el mundo, sino la VARIACIÓN, puede esperarse de ella, una MUDANZA favorable a la VIDA SOCIAL (pág. 209).

La segunda sentencia indica que tal cambio o mudanza puede ocurrir porque las personas no somos eternas, y los niños y jóvenes podrían aprender costumbres diferentes, cónsonas a la vida social. En cuanto a la tercera y cuarta sentencias, éstas se refieren a la sostenibilidad y legitimidad de la autoridad republicana. Según Rodríguez (1982e): PARA UNA AUTORIDAD CONSTANTE UNA EDUCACIÓN SOCIAL: “...No habrá JAMAS! verdadera sociedad, sin Educación Social ni Autoridad constante, sin Costumbres Liberales. ¡Si queremos hacer REPÚBLICAS! ¡Debemos emplear medios...TAN NUEVOS! ¡Como es NUEVA! La Idéa de VER por el BIEN de TODOS" (pág. 210).

Rodríguez muestra con sencillez y contundencia el papel de la educación social y la escuela como lugar de creación de la nueva sociedad y sede de un movimiento de creación de nuevos valores y tratos, distintos a la tradición y a la imitación sumisa, pero basados en un principio jerárquico de interdependencia de las capacidades humanas, por encima de privilegios, autoridades y costumbres. Ese principio máximo se encuentra en una sentencia de otra obra de Rodríguez (1982f), llamada: "Luces y Virtudes Sociales" (pág. 67); el cual puede llamarse principio jerárquico de interdependencia de facultades y vale la pena referirlo aquí. Expone Rodríguez (1982g), que su PRINCIPIO JERÁRQUICO DE INTERDEPENDENCIA DE FACULTADES: "no hay facultad propia que pueda ejercerse sin el concurso de facultades ajenas" (pág. 82). Tal fórmula de asociación, de libertad complementada, de autonomía agradecida, debe practicarse y aprenderse en la escuela. Y son los niños y jóvenes, con maestros formados, quienes lo aprenderían más fácil y rápido.

Luego de las premisas fundacionales antes señaladas el autor entra a 
desarrollar sus consejos. Éstos tienen que ver en cómo convertir el Colegio Latacunga en ejemplo para ese cambio. Recomienda que el Rector y sus amigos influyan en una Ley en favor del sostén económico y propagación sostenible de la Escuela Social. Porque la escuela debe asegurar fondos en fincas rurales. En otro consejo propone que el Congreso del Ecuador pueda imponer una contribución especial para el financiamiento de tales escuelas, sus infraestructuras y pago de maestros.

En materia curricular Rodríguez (1982h): propone abrir cátedras de Castellano y "Quichua”, en vez de latín. Debe abrir cátedras de Física, Química e Historia Natural, en vez de Teología, Derecho y Medicina. Y propone que la escuela debe contar con dos fábricas de loza y vidrio y una maestranza de albañilería, carpintería y herrería (pág. 211). A favor del "Quichua", argumenta con fuerza: “¿Es posible? Que vivamos con los Indios, sin entenderlos?!” (pág. 114); y con "Ciencias Exactas i de Observación, los jóvenes aprenderían a apreciar lo que PISAN, i se abririan MUCHAS CARRERAS" (pág. 215).

La idea de una maestranza en el colegio es muy relevante. Se trata para Rodríguez (1982i): de una unidad de práctica de oficios y de economía dentro del colegio, en la que se enseña a producir con recursos locales, se recolectan fondos para el colegio y se presta servicio a las comunidades de la ciudad. Los jóvenes pasan dos años de instrucción en carpintería, herrería y albañilería. El régimen de enseñanza es intensivo e interno, trabajando y viviendo en la maestranza, con maestros especialistas contratados de otras ciudades, incluso extranjeros, con todos los gastos pagados por el colegio. Una vez terminado el período de aprendizaje de los dos años de estudio, los tres mejores alumnos pasan a substituir a los maestros traídos de otras partes. En ese momento el colegio puede plantearse "cederles la propiedad" de la maestranza; bajo la condición que mantenga su propósito, y la mitad de las utilidades sean del colegio, por un plazo de cinco años. Tal porcentaje bajaría de cincuenta a diez, en los siguientes diez años (pág. 221). 
Se trata de una perspectiva de autofinanciamiento y de producción dentro del sistema educativo, en la medida en que se enseña artesanías con sentido práctico, productivo y de integración social de niños y jóvenes excluidos. Tareas útiles y económicas, todas ellas unidas a las labores de la enseñanza que complementan su propuesta de la escuela social. Al tiempo que incuba asociaciones para la producción y el emprendimiento, basadas en el talento popular.

Rodríguez se detiene en consideraciones muy concretas para el plan de operaciones de la maestranza. Hace recomendaciones sobre la madera y su tratamiento, sobre las casas de Latacunga y la posibilidad de mejorarlas; así como en materia de prevención de los estragos de los temblores, a través de mejores reforzamientos de las construcciones. En otras palabras, se plantea poner en concurso facultades ajenas, con facultades propias creadas por la escuela. Los servicios y productos de buena calidad y costos justos satisfacen solicitudes de la comunidad y se crea aprendizaje y trabajo desde la escuela. Concretamente, para Rodríguez (1982j), LA SOCIABILIDAD AMERICANA consiste en que:

La Escuela Primaria dará REGLAS DE CONDUCTA...en JENERAL... la Maestranza PONDRÁ en PRÁCTICA... las que le TOQUEN, i el Colejio habrá dado en lo que NADIE! hasta aquí, que es, en hacer ver... que en toda OCUPACIÓN...EN TODA EMPRESA...ha de rejir la Idea de la SOCIABILIDAD." Ya que si la Primera Escuela fuese pensada así por todos: no habría AMOS, porque no habría ESCLAVOS... LOS AMERICANOS estarían viendo el Suelo que pisan, no mirando las Estrellas, esperando lo que está en el Orden, nó que el Olmo dé Peras buscando su vida en el trabajo, no rezando el padre nuestro, para pedir que almorzar, contando con lo que tienen, nó con lo que les promete, el que no tiene que dar (págs. 222-225).

\section{Discusión}

La propuesta de Rodríguez en "Consejos de amigo, dados al Colegio 
Latacunga" conforma la línea de un proyecto pedagógico fundamentado, articulado y detallado, que fue elaborado hacia el año 1850 para la institucionalidad educativa de la sierra ecuatoriana. Puede decirse que se trata de la proyección de las principales experiencias de invención institucional de Rodríguez en América, llevadas adelante en Caracas en el año 1794, en Bogotá en el año 1823, y en Chuquisaca en el año 1826, esta vez pensadas para el contexto de la sierra andina ecuatoriana de Latacunga.

En este proyecto la educación no es enseñanza ni instrucción solamente, es social, es decir, sobre todo construcción social republicana. La educación es la estrategia institucional republicana para crear la asociatividad o sociabilidad requerida de la autoridad republicana. Una asociación donde lo principal es la relación de interdependencia entre las "facultades" o capacidades de los asociados para sustituir la dependencia de la monarquía, la colonia y los nuevos amos. Por esta misma razón el enfoque que se enfatiza busca romper cierta educación testamentaria y conservadora para incluir a los auténticos "dueños del país". Es decir, la educación está centrada en un nuevo sujeto histórico: el pueblo y no la casta de los viejos y nuevos amos. Y en un sistema de acceso a todos desde la escuela primaria para impedir que el sistema testamentario, basado en la herencia, siguiese reproduciendo las desigualdades coloniales de la tradición colonial y clerical. Solo así, interpreta Paladines (2008d): se puede fundar una república y convivir sin guerras (pág. 160).

La más clara demostración de este argumento se encuentra en su primer consejo: quienes ante todo deben ir a la escuela son los indígenas. Son ellos quienes constituían la mayor población popular de ese tiempo en la sierra ecuatoriana. Y se propone incorporarlos a través de su propia lengua el Kichwa, y del Castellano (Quichua en el texto de Rodríguez), no para adoctrinarlos en una religión como ya lo hacía la Iglesia, sino para acogerlos como ciudadanos de plenos derechos, para entenderse en esta nueva relación 
propuesta por la república, que comienza por reconocer la lengua y la cultura de los asociados. Una relación que podría haberse llamado -intercultural bilingüe-. Pero que no la llamó así Rodríguez, sino social, porque la propuso en tanto sentido de asociación entre personas y grupos de diferentes culturas, estratos, procedencias y capacidades, unidos en una conciencia republicana.

Así concebida, la educación no podía ser sino laica y pública. Principios que hoy pueden parecer normales pero que, en el contexto de las sociedades recién liberadas militarmente de la monarquía, donde la educación era clerical y reservada para la casta de grandes propietarios y sus herederos, resultaron cuando menos disruptivos y escandalosos. Por lo cual se entendía que su cabal implementación exigía una alta prioridad política que nunca se alcanzó.

De manera que la transformación social para fundar las repúblicas apenas establecidas militarmente se planteaba a través de la educación en la escuela primaria. La primera escuela es la que debe, ante todas las cosas, ocupar la atención de un gobierno. Preparar a los niños para vivir en sociedad y sin pobreza económica ni cultural y con participación de sus padres. La transformación de la sociedad comienza en una escuela primaria que corte la dependencia colonial que persistía en las costumbres, tradiciones y formas de trabajo. La escuela debe crear y enseñar autonomía. Por eso se propone también enseñarlos a trabajar.

Esto tiene otro propósito: el sostenimiento mismo del sistema escolar, lo cual le permitiría ser menos oneroso para la República. Por esas razones su proyecto se visualiza mucho mejor en el campo que en la ciudad, ya que el propósito fundador debe estar más cerca de la gente indígena y pobre (que en ese tiempo era fundamentalmente rural) y de la agricultura y de las tierras cultivables.

Es una forma también de distanciarse del sistema testamentario que rige la ciudad. A este respecto ha sido señalado que la utopía en Rodríguez adquiere una dimensión de aislamiento para la invención social, ya que se trata 
de realizarse a través de sus habitantes en "colonias" dentro de su propio territorio. Una colonización con sus propios habitantes a los fines de hacerse dueños de sí mismos y de su país a través del estudio y del trabajo. La finalidad es aislarse de la imitación del mundo europeo para crear desde la experiencia contextual y propia de los americanos. Para lo cual viene muy a colación la sentencia "inventamos o erramos", refrendada en el título del libro de compilaciones de Cúneo (1982b): que nos ha servido para el estudio (pág. 5).

En cuanto a la forma de enseñar, Rodríguez postula la tesis de que sin formar buenos maestros no vale la pena crear escuelas. No pueden seguir siendo los maestros unas bocinas y sus alumnos unos loros. Propone maestros que tengan una pedagogía ligada al arte, a la atención lúdica de los niños en búsqueda del interés de los alumnos por los temas, a la práctica de oficios y labores en maestranza, a la combinación equilibrada entre disciplina, al juego y al trabajo. Todo ello, como lo remarca Paladines (2008e): desde la experiencia de los alumnos, en un proceso de enseñanza que privilegie el aprendizaje con una metodología de experimentación y reflexión (págs. 165166). De hecho, el investigador Kohan (2013): cree que Paolo Freire pudo muy bien haber leído a Rodríguez, por la cercanía en varios de los planteamientos (pág. 122); o en todo caso, refiere Paladines (2008f): lo antecede en tierras americanas en la denuncia de la educación bancaria (pág. 163).

Para Calderón y Fierro (2013b): Rodríguez formula un enfoque educativo "negativo" (pág. 27); ya que de lo que se trata no es de ofrecer a los alumnos un conocimiento de sus deberes a manera de envoltura o barniz, sino de perfeccionar sus facultades propias para hacer florecer su naturaleza humana Una postura probablemente inspirada en "Emilio o de la Educación" de Rousseau.

La idea del "buen salvaje" está presente en su acercamiento a una educación cercana a la naturaleza, al campo, a la agricultura, a la pobreza de recursos, a los oprimidos. En efecto, Uslar-Pietri (1981e): interroga la 
interpretación de Rodríguez, así "era el hombre bueno por naturaleza o había que enseñarlo a ser bueno" (pág. 40). Pregunta a la que se responde con la confianza puesta en los menos formados por la educación tradicional y colonial.

\section{Conclusiones}

El texto analizado de Rodríguez confirma su visión secular y social, frente al predominio de la familia patriarcal, la Iglesia y la tradición colonial en la sociedad de repúblicas establecidas, pero no fundadas, como le gustaba decir. Lo cual explica, en parte, que sea tan desconocido su aporte y que haya recibido tanto rechazo en su época y aún en la actualidad. Si bien el cristianismo católico en América abrió las puertas de su templo a todos los grupos sociales colonizados y buscó su integración, lo hizo en función de una jerarquía clasificadora de la diversidad. Había que someterse a la jerarquía de un dogma, una sola lengua y una sola raza. Rodríguez propone formalmente, como se ha mostrado, y por primera vez a mediados del siglo XIX, según lo expuesto por Paladines (2008g): romper con esa "educación testamentaria" (pág. 162); e incorporar las lenguas indígenas en la escuela. Vale notar que un autor muy importante como Martín-Barbero (2012): propuso ese mismo camino de: no inferiorizar al "otro", para lograr la comunicación a través de la cultura (págs. 80-81); pero lo hace siglo y medio después de "Los Consejos de Amigo".

Rodríguez propone también medios de producción en la escuela, para garantizar mayor autonomía y utilidad de la escuela popular, como aprendizaje de una nueva sociedad. Aprendizaje que se basa en un principio fundacional asociativo y no de agregados individuales, fundado en la interdependencia de las capacidades o facultades humanas (hoy llamadas también competencias), donde para ejercer las propias, se requiere el concurso de las ajenas. Principio valorado, aplicado y practicado en su propuesta de organización, currículo, 
didáctica y producción de una Escuela Social.

Tiene mucho sentido entonces que Bolívar (1824b): haya llamado a Rodríguez el "Sócrates de Caracas, mí Sócrates" (pág. 172). Para GarcíaBacca (1990b), de formación filosófica, ese símil de Sócrates con Rodríguez, tiene mucho sentido ya que una de las acusaciones en el juicio contra Sócrates, el de Atenas, fue: "no creer en los dioses en que cree la ciudad" (pág. XIII); y eso mismo ocurrió con el Sócrates caraqueño.

En su lecho de muerte, en una vivienda mísera de Amotape, a finales de febrero del año 1854, su acompañante Camilo Gómez, y fuente de este testimonio, cree que le hace falta un cura para confesar al maestro. Cuando el cura llegó y requirió su confesión, Rodríguez le dijo según Rumazo (2006c): que "no tenía más religión que la que había jurado en el Monte Sacro" (pág. 133).

Ciertamente, Rodríguez creía firmemente en la razón y en la libertad. Para Paladines (2008h): era un hombre de la llustración más romántica (pág. 161). Creía además que nacemos con grandes bondades y potencialidades pero que las tradiciones, herencias y costumbres nos vuelven repetitivos, rutinarios, instintivos, lo cual tiene una clara resonancia de la idea del "buen salvaje". Por eso su insistencia en alumbrar, dar luces y resucitar las palabras muertas.

Pero su relación con la alteridad siempre fue problemática. Se cambió su nombre por Samuel Robinson cuando vivió en Norteamérica y en Europa y luego volvió a retomar su nombre de Simón Rodríguez al regresar a Suramérica. Un juego de espejos e identidades que también atraviesa la cultura latinoamericana. Pero este Robinson no logra, a su regreso, su proyecto de colonizar la isla, como si lo hizo Crusoe. A Rodríguez no le queda más que, aislarse del mundo o vagar eternamente de un lado a otro, convirtiéndose él mismo en una isla, en un naufragio. A lo que Calderón y Fierro (2013c): Ilamaron la "quijotización de Robinson" (pág. 32). Ante los 
poderosos mostró desconfianza, terquedad y distancia, y ante los indígenas oprimidos, reconocimiento, comunicación e incomprensión. Simón Rodríguez quedó aislado, como las tierras imaginarias de la utopía, como lo estuvo Robinson en su isla.

A más de siglo y medio de su propuesta para el Colegio Latacunga su rescate como el pionero de una educación pública y republicana ecuatoriana y americana sigue pendiente, puede que este estudio contribuya a ubicarlo adecuadamente en la historia de la educación andina y ecuatoriana.

\section{Referencias}

Alfaro, R. (1999). Comunicación y Educación: una alianza estratégica de Ios nuevos tiempos. Signo y Pensamiento, 18(34), 9-18, ISSN: 01204823; e-ISSN: 2027-2731. Recuperado de:

http://revistas.javeriana.edu.co/index.php/signoypensamiento/article/vi ew/2849

Bolívar, S. (1824a,b). Doctrina del Libertador. Madrid, España: Fundación Biblioteca Virtual Miguel de Cervantes. Recuperado de: http://www.cervantesvirtual.com/obra-visor/doctrina-del-libertador-0/html/ff6f5f94-82b1-11df-acc7-002185ce6064 30.html\#I 57

Calderón, T., \& Fierro, J. (2013a,b,c). Robinson, Rousseau y Rodríguez: el naufragio de la utopía latinoamericana en La Isla de Robinson de Arturo Uslar Pietri. Revista Chilena de Literatura, (83), 5-34, e-ISSN: 0718-2295. Recuperado de:

https://revistaliteratura.uchile.cl/index.php/RCL/article/view/26975

Cúneo, D. (1981a,b). Aproximación a Simón Rodríguez. En Rodríguez, S. (1982). Inventamos o erramos, págs. 11-34. Caracas, Venezuela: Monte Ávila Editores.

García-Bacca, J. (1990a,b). Prólogo. En Rodríguez, S. (1990). Sociedades Americanas, págs. XI-XLIII. Caracas, Venezuela: Biblioteca Ayacucho. 
Grases, P. (1981). La Tradición Humanística. Obras de Pedro Grases. Barcelona, España: Ediciones Seix Barral.

Gutiérrez, A. (2011). Simón Rodríguez, América en los sueños de su razón. Anales de Literatura Chilena, (16), 13-38, e-ISSN: 0717-6058. Recuperado de:

https://dialnet.unirioja.es/servlet/articulo?codigo $=4239322$

Kohan, W. (2013). El maestro inventor. Simón Rodríguez. Buenos Aires, Argentina: Editorial Miño y Dávila.

Martín-Barbero, J. (2012). De la comunicación a la cultura: perder el “objeto" para ganar el proceso. Signo y Pensamiento, 30(60), 76-84, ISSN: 0120-4823; e-ISSN: 2027-2731. Recuperado de:

http://revistas.javeriana.edu.co/index.php/signoypensamiento/article/vi $\underline{\mathrm{ew}} / 2412$

Paladines, C. (2008a,b,c,d,e,f,g,h). Simón Rodríguez: El Proyecto de una Educación Social. Educere, 12(40), 159-169, e-ISSN: 1316-4910. Recuperado de: http://www.redalyc.org/articulo.oa?id=35604020

Prieto, D. (1987). Utopía y comunicación en Simón Rodríguez. Quito, Ecuador: Centro Internacional de Estudios Superiores de Comunicación para América Latina - CIESPAL.

Rodríguez, S. (1982a,b,c,d,e,f,g,h,i,j). Inventamos o erramos. Caracas, Venezuela: Monte Ávila Editores.

Rotker, S. (1995). Simón Rodríguez, tradición y revolución. En González Stephan, J. Lasarte, G. Montaldo, M. Daroqui (Eds.) Esplendores y miserias del siglo XIX. Cultura y Sociedad en América Latina, págs. 161182. Caracas, Venezuela: Monte Ávila Editores.

Rumazo, A. (2006a,b,c). Simón Rodríguez maestro de América. Biografía breve. Caracas, Venezuela: Publicación digital del Ministerio de Comunicación e Información. Recuperado de:

http://www.fundayacucho.gob.ve/2017/11/14/simon-rodriguez-maestro- 
de-america/

Urosa, N. (2015), Simón Rodríguez y la capacidad transformadora del Arte

Social. Tiempo y Espacio, (63), 211-230, e-ISSN: 1315-9496.

Recuperado de: http://www.scielo.org.ve/pdf/te/v25n63/art12.pdf

Uslar-Pietri, A. (1981a,b,c,d,e). La Isla de Robinson. Barcelona, España:

Editorial Seix Barral. 
Silverio Jesús González Téllez

e-mail: silverio.gonzalez@unae.edu.ec

Nací en Valencia, Venezuela, el 23 de abril del año 1956.

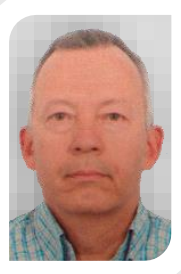
Soy sociólogo, con doctorado interdisciplinario en el área de las Ciencias Sociales; Fui profesor en la Universidad Simón Bolívar (USB) de Caracas, por veinte años donde ejercí la docencia e investigación como profesor Titular, Jefe de departamento, Director de carrera, Director de instituto de investigaciones y miembro del Consejo Superior; Actualmente soy profesor Titular Principal 1, y docente de Enseñanza y Aprendizaje del Medio Social en la Universidad Nacional de Educación de Ecuador (UNAE); He sido Coordinador Académico de Postgrados en la misma universidad y coordino para la UNAE, la participación en el proyecto internacional Erasmus, titulado de la Formación tradicional a la innovación en la formación de maestros, en convenio con la Universidad de Barcelona (UB), y más de veinte academias europeas y latinoamericanas.

El contenido de este manuscrito se difunde bajo una Licencia de Creative Commons ReconocimientoNoComercial-Compartirlgual 4.0 Internacional 